\title{
Tissue donation after death in the accident and emergency department: an opportunity wasted?
}

\author{
H P Magrath, L J Boulstridge
}

\begin{abstract}
Objective-To investigate whether the accident and emergency department (A\&E) is a potential source of tissues for donation, from non-heart beating donors (NHBDs).

Methods-A telephone survey of 30 A\&E departments was conducted to determine current tissue harvesting practices from NHBDs. The potential number of tissue donors in our own medium sized district general hospital A\&E department was estimated. Senior nursing staff were asked to complete a questionnaire to establish their knowledge, attitudes, and experience of tissue harvesting from NHBDs.

Results-Only seven of the 30 A\&E departments surveyed (23\%) had an active involvement in requesting tissue donation after a sudden death. Several others had limited experience. The level of involvement was unrelated to department size. In our own A\&E department, there were 110 deaths in 1995. Tissue donation had occurred on just three occasions. However, departmental staff attitudes towards reducing this shortfall were positive. Conclusions-The A\&E department is a resource of tissues for donation, which is currently under used.

( $F$ Accid Emerg Med 1999;16:117-119)
\end{abstract}

Keywords: tissue donation; non-heart beating donor

Tissues such as corneas, heart valves, and bone may be harvested from cadaveric or non-heart beating donors (NHBDs) many hours after death. Corneas can be harvested up to 24 hours after death from people of any age provided the donor has no history of intraocular surgery, corneal scarring, or recent eye infection. Implanted human heart valves may have advantages over prosthetic valves and reduce the need for anticoagulation. Human heart valves may be harvested up to 72 hours postmortem from donors between 6 months and 60 years of age. Bone transplantation is a relatively new technique in the UK. Whole bone may be employed where amputation would otherwise be indicated, bone rings may provide structural support, and ground bone can be used as cement. The age range for bone donation is 18 to 75 years. Bone can be retrieved, provided there is no evidence of malignancy, bone disease, or major fracture, up to 48 hours after death.

National data on supply and demand for transplantation tissues is limited. In the UK, approximately 4000 corneal grafts are per- formed annually. ${ }^{1}$ In 1997, 3583 corneal donations were made to the Bristol and Manchester eye banks, $16 \%$ fewer than in the previous year (data supplied by the Bristol Eye Bank, 1998). There are currently no national figures for heart valve and bone transplantation from NHBDs. However, individual tissue banks report a constant demand for these tissues which can not always be met (data supplied by the Bristol Tissue Bank and the Yorkshire Regional Tissue Bank, 1998). Heart valves, for example, are matched with recipients, by size, and the supply of very large and small, that is paediatric, valves is often limited.

Sudden death occurs frequently in accident and emergency (A\&E) departments and many of these patients could potentially be suitable for non-heart beating tissue donation. Furthermore the act of donation can be a positive means of dealing with grief, particularly after an unexpected bereavement. ${ }^{2}$. In contrast to organ transplantation from heart beating donors (after the diagnosis of brain stem death), tissue harvesting from cadavers has received little coverage in the medical and national press. $^{3}$ Health care professionals, in general, are less aware of this option. ${ }^{4}$

This study explores current awareness and practice of non-heart beating tissue harvesting in a sample of A\&E departments in the UK. We also predicted the potential contribution our medium sized A\&E department could have on increasing the number of tissue donations made.

\section{Methods}

The study consisted of three parts:

(1) Thirty British A\&E departments were surveyed by telephone. Departments were classified into three sizes by the number of annual new attendances in 1995 ( $<40000$, $40000-75000$, and >75 000). ${ }^{5}$ Ten departments of each size were selected, at random, covering the regional health authorities in Britain. A series of open and closed questions were asked as part of a semistructured telephone interview with the senior nurse in charge. The interview was designed to assess the awareness of and involvement in tissue donation from NHBDs.

(2) A computer search of $A \& E$ records at the Derbyshire Royal Infirmary identified the deaths that occurred in the department, and those patients brought in dead during 1995. The number of NHBD tissue donors for 1995 was obtained from the transplant coordinator for the Nottinghamshire and South Derbyshire region. Using age criteria alone, the potential number of cornea, bone, and heart valve donors was calculated. 


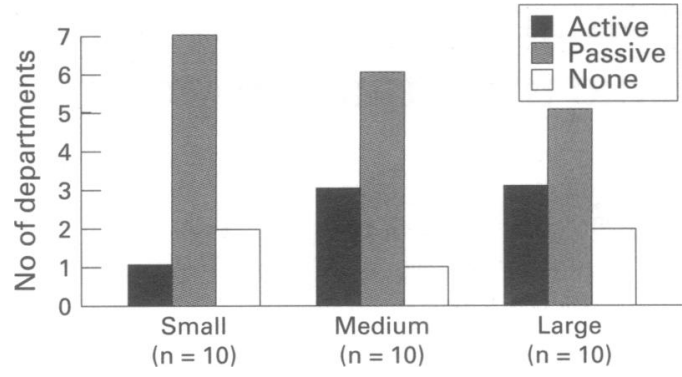

Figure 1 Involvement in tissue harvesting by $A \mathcal{E} E$ department size.

(3) A questionnaire was sent to the 12 senior nursing staff in our $A \& E$ department to determine their attitudes towards, and experience of, tissue harvesting from NHBDs.

\section{Results}

TELEPHONE SURVEY

A\&E departments fell into three categories: those with no experience of tissue procurement from NHBDs (no involvement); those which had arranged harvesting, but only when initiated by a relative (passive involvement); and those whose staff members usually raised the subject with bereaved relatives (active involvement).

Seven $A \& E$ departments (23\%) had active involvement, $18(60 \%)$ were passively involved, and five $(17 \%)$ had no involvement. The degree of involvement in relation to department size is shown in fig 1 .

Twelve of the $30 \mathrm{~A} \& \mathrm{E}$ departments (40\%) had recently held, or were planning, training and education in this area for their staff.

Five of the interviewed senior nurses were aware that their department had a written policy regarding tissue donation: of these, three described an active involvement in tissue procurement and two were passively involved. Seven others knew of informal guidelines: four were actively involved departments and three passively.

Of the 18 departments with no policy (60\%), 13 described passive involvement. In 24 departments $(80 \%)$, the interviewee knew how to contact the local transplant coordinator.

DERBYSHIRE ROYAL INFIRMARY A\&E DEPARTMENT There were approximately 65000 new patients in 1995. The department's computer recorded 110 deaths that year. In 86 cases $(78 \%)$ the age of the deceased had been documented.

Using age criteria alone, there were potentially 86 cornea, 65 bone, and 35 heart valve donors in 1995. Of these, just three patients actually donated tissues. In each of these cases, it was the relatives of the deceased who had requested that donation be considered.

The 12 senior nurses in the Derbyshire Royal Infirmary A\&E department were sent questionnaires. Of these, nine $(75 \%)$ were returned completed. Six nurses $(50 \%)$ had discussed tissue donation with bereaved relatives in the $A \& E$ setting. In each case it had been the family who had initially inquired about the possibility of donation. Only one member of staff felt sufficiently knowledgeable to broach the subject. All nine stated that with adequate training, consultant support and a departmental policy, they would consider initiating a discussion with newly bereaved relatives.

\section{Discussion}

This study has identified wide variation in the involvement of $\mathrm{A} \& \mathrm{E}$ departments in tissue harvesting from NHBDs. This appears to be unrelated to the size of the department. Enthusiasm, staff awareness, and the existence of a departmental policy seem to be more important factors in fostering active discussion with relatives. Hassan et al also showed that even within one hospital, interdepartmental variation in retrieval rates occurred and this appeared to be linked with staff commitment to the transplantation programme. ${ }^{6}$

Most departments (60\%) were only passively involved, that is tissue donation was proffered by the relatives. Our own department fell into this category and yielded only three donations in 1995. The questionnaire to local nursing staff revealed that the lack of active requests was, in part, due to the absence of a departmental policy and relevant training. Siminoff et al reported that whereas most of 206 health care professionals interviewed in a Pittsburgh hospital had received some training regarding organ harvesting from heart beating donors, none had received any on tissue harvesting from NHBDs. ${ }^{4}$

One A\&E department in our survey reported a corneal retrieval rate of almost $100 \%$ after a shortage was reported to them by their local eye bank. This suggests that when health care professionals take an active approach, retrieval rates can be greatly improved.

A sudden, unexpected death is distressing for both the newly bereaved and the health care professionals involved. Reluctance to ask relatives about donation is therefore not surprising. Donation can help with the grieving process, however, in knowing that some good has come from a relative's death. ${ }^{2}$ Failure to discuss the option of tissue donation with the bereaved may deny them a future source of comfort.

Health care professionals may be concerned that raising the subject of tissue donation could be considered inappropriate by the family at this sensitive time. ${ }^{7}$ Comments made by our interviewees suggested that even when relatives decided not to permit donation, the request caused no offence. In one study of relatives' views, $73 \%$ of respondents stated that they would not have minded being asked about organ donation in $A \& E .^{8}$ The unexpected nature of a death in $A \& E$ can make the task of discussing donation difficult. However, this does not appear to increase the refusal rate. ${ }^{6}$

Discussion regarding tissue donation with the newly bereaved can be initiated in a number of ways. Finding a donor card among the deceased's possessions makes requesting donation easier. ${ }^{9}$ Written information can be included in the literature which is usually given to newly bereaved relatives by the A\&E department and this may help to introduce the subject. In view of the fact that tissue may be successfully donated up to 72 hours after 
death, this also allows the relatives time to make their decision. Information could also be provided in the relatives' room or in patient waiting areas. $^{8}$

In conclusion, $A \& E$ departments have substantial potential to contribute to the supply of tissues required for transplantation. We suggest that the key to realising this potential is appropriate training to health care professionals coupled with an accessible agreed written policy.

Our thanks to the staff of the A\&E department at the Derbyshire Royal Infirmary; D Cunningham, the Transplant Coordinator for Nottingham and South Derbyshire, and Mr A Bleetman, Consultant in A\&E, Heartlands Hospital, Birmingham, for his invaluable advice.

1 United Kingdom Transplant Support Service Authority. Statistics prepared by UK Transplant Support Service Authority from the National Transplant Database maintained on behalf of from the National Transplant Database maintained on behat
the UK transplant community. Bristol: UKTSSA, 1998.
2 Smith-Brew S, Yanai L. The organ donation process through a review of the literature, part 2. Accident and Emergency Nursing 1996;4:97-102.

3 Riker RR, White BW. The effects of physician education on the rates of donation requests and tissue donation. the rates of donation requestation 1995;59:880-4.

4 Siminoff LA, Arnold R, Miller DS. Differences in the procurement of organs and tissues by health care professionals. Clin Transpl 1994;8:460-5.

5 Royal College of Surgeons. British Association for Accident and Emergency Medicine directory 1996. Lavenham: Lavenham Press, 1996.

6 Hassan TB, Joshi M, Quinton DN, et al. Role of the accident and emergency department in the non heart beating donor programme in Leicester. $\mathcal{F}$ Accid Emerg Med 1996;13:321prograr

7 Gaber AO, Hall G, Phillips DC, et al. Survey of attitudes of health care professionals toward organ donation. Transplant Proc 1990;22:313-15.

8 Wellesley A, Glucksman E, Crouch R. Organ donation in the accident and emergency department: a study of relatives' views. $\mathcal{F}$ Accid Emerg Med 1997;14:24-5.

9 Grover LEK. The potential role of accident and emergency departments in cadaveric organ donation. Accident and Emergency Nursing 1993;1:8-13. 